\title{
Effects of Finishing Materials against Carbonation and Corrosion Condition of Model Building Exposed to Outdoor Conditions for 30 Years
}

\author{
Koichi Matsuzawa ${ }^{1}$, Osamu Senbu ${ }^{2}$, Kei-ichi Imamoto ${ }^{3}$, Chizuru Kiyohara ${ }^{4}$, \\ Kotaro Etchuya ${ }^{5}$ and Kaori Nemoto ${ }^{6}$ \\ ${ }^{1}$ Dept. of Building Materials and Components, Building Research Institute, Japan, \\ matsu@kenken.go.jp \\ ${ }^{2}$ Faculty of Engineering, Hokkaido University, Japan, senbu@eng.hokudai.ac.jp \\ ${ }^{3}$ Faculty of Engineering, Tokyo University of Science, Japan, imamoto@rs.kagu.tus.ac.jp \\ ${ }^{4}$ Faculty of Engineering, Tokyo University of Science, Japan, ckiyo@rs.tus.ac.jp \\ ${ }^{5}$ Japan Building Coating Material Association, Japan, ecchuya@nsk-web.org \\ ${ }^{6}$ Housing Dept., National Institute for Land and Infrastructure Management, Japan, \\ nemoto-k92ta@mlit.go.jp
}

\begin{abstract}
A model building made out of concrete block specimens whose surfaces were coated with various finishing materials was constructed for the outdoor exposure test. After 30 years of outdoor exposure, the deterioration of finishes and their carbonation and corrosion inhibition effects were investigated. As a result, the following conclusions were obtained: Though the deterioration levels differed depending on their types and thickness, all finishing materials showed some kind of deterioration after 30 years' long-term outdoor exposure. The progress of carbonation and corrosion are prevented when the surface is coated with finishing materials of sufficient thickness or waterproof effect. Regarding the relationship between corrosion depth and carbonation depth, corrosion is initiated after the carbonation front reaches the area. It usually takes a while to initiate corrosion in the carbonated area, not immediately after the carbonation reaction. When the concrete surface is properly coated with finishing material, corrosion may not be initiated in non-carbonated area in concrete where the $\mathrm{pH}$ level is not lowered.
\end{abstract}

Keywords: Finishing Materials, Outdoor Exposure, Carbonation, Corrosion.

\section{Introduction}

The durability of Reinforced concrete (RC) buildings are basically determined by the presence or absence of steel corrosion. In order to prevent corrosion of steel in concrete, degradation factors such as carbon dioxide $\left(\mathrm{CO}_{2}\right)$ and chloride ions need to be prevented from penetrating into concrete. In many RC buildings, finishes are applied to concrete surfaces, which prevent the penetration of degradation factors. While many studies have been reported on the preventive effects of finishing materials based on accelerated testing, little is based on the long-term exposure to the outdoor conditions (Hasegawa et al., 2002, 2017).

In this study, a model building made out of concrete block specimens whose surfaces were coated with various finishing materials was constructed for the outdoor exposure test. After 30 years of outdoor exposure, the deterioration of finishes and their carbonation and corrosion inhibition effects were investigated. 


\section{Experiment Overview}

\subsection{Outline of Specimens}

Table 1 shows the materials used for concrete, and Table 2 shows the mix proportion and properties. The water cement ratio (w/c) is 0.55 and 0.70 , and unit water content was 176 $\mathrm{kg} / \mathrm{m}^{3}$. To measure corrosion depth by the corrosion indicator method (Senbu et al., 1987), iron particles were mixed to some concrete specimens before casting to make them serve as corrosion indicators. Chloride ions were also premixed in some specimens of w/c ratio 0.70 at the concentrations of $0.3,0.6$, and $1.2 \mathrm{~kg} / \mathrm{m}^{3}$ by dissolving $\mathrm{NaCl}$ in water to examine the effect of chloride on concrete. The iron particles had diameters of 0.15 to less than $2.5 \mathrm{~mm}$, used as a partial replacement of fine aggregate at $20 \%$. Concrete specimens of $100 \times 100 \times 400 \mathrm{~mm}$ in size, whose shapes were designed to be piled up to build the model building, were prepared (Figure 1). After demolding, the specimens were cured in $20^{\circ} \mathrm{C}$ water for 28 days, followed by an atmospheric curing period of 42 days at $20^{\circ} \mathrm{C}, 60 \%$ R.H. Surface finishing materials were then applied to the specimens.

Table 1. Materials.

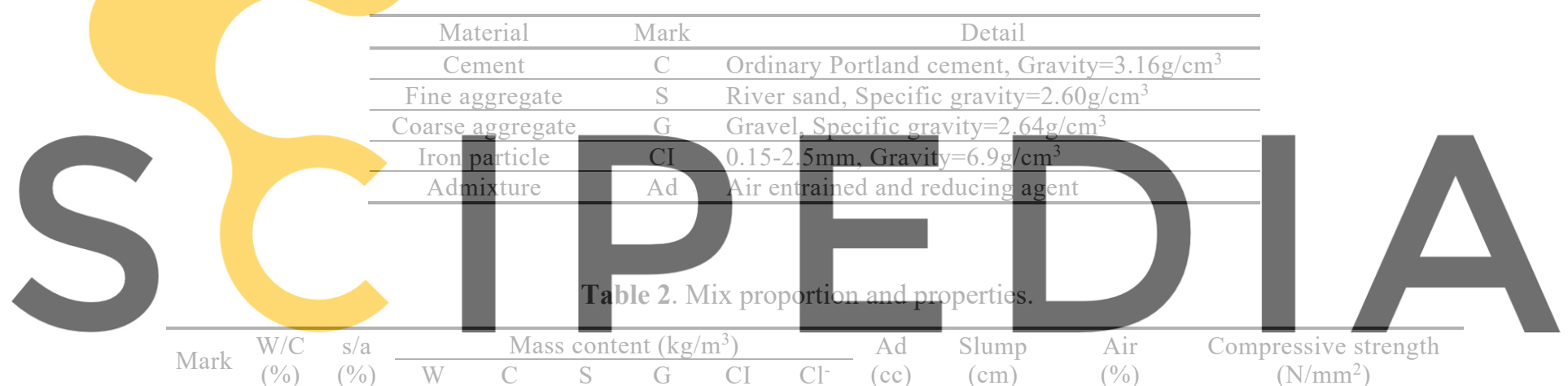

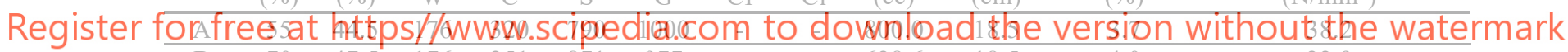

\begin{tabular}{ccccccccccccc}
\hline $\mathrm{B}$ & 70 & 47.5 & 176 & 251 & 871 & 977 & - & - & 628.6 & 18.5 & 4.0 & 22.9 \\
\hline $\mathrm{C}$ & 55 & 44.5 & 176 & 320 & 632 & 1000 & 420 & - & 800.0 & 15.5 & 3.4 & 40.5 \\
$\mathrm{D}$ & 70 & 47.5 & 176 & 251 & 697 & 977 & 461 & - & 628.6 & 15.5 & 3.7 & 27.4 \\
\hline $\mathrm{E}$ & 70 & 47.5 & 176 & 251 & 697 & 977 & 461 & 0.3 & 628.6 & 15.5 & 3.6 & 29.5 \\
\hline $\mathrm{F}$ & 70 & 47.5 & 176 & 251 & 697 & 977 & 461 & 0.6 & 628.6 & 16.0 & 3.6 & 27.6 \\
\hline $\mathrm{G}$ & 70 & 47.5 & 176 & 251 & 697 & 977 & 461 & 1.2 & 628.6 & 15.5 & 3.5 & 29.1 \\
\hline
\end{tabular}

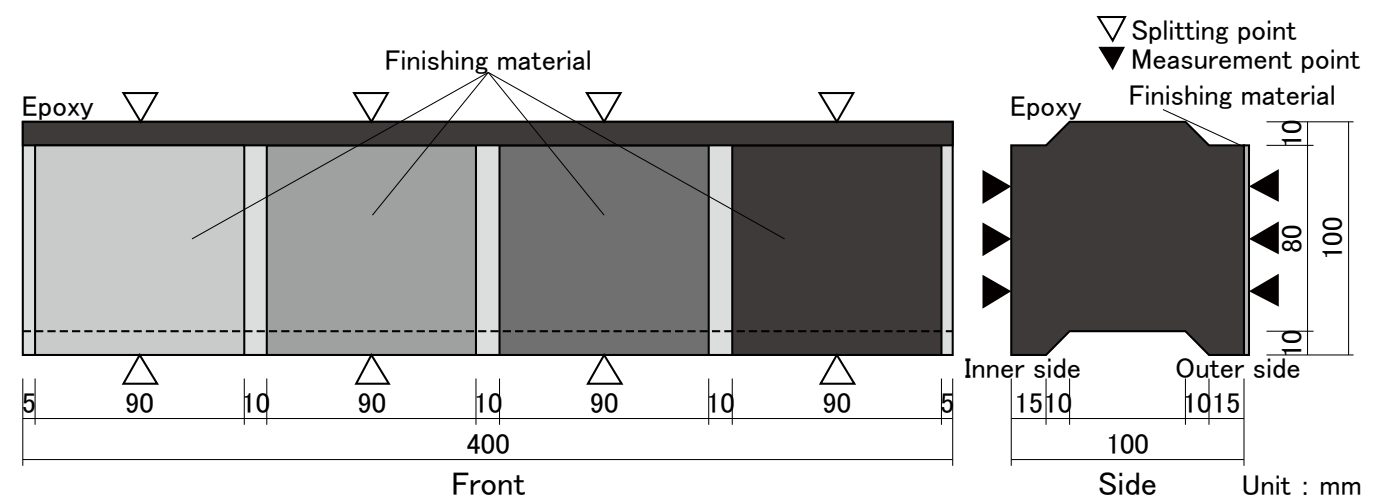

Figure 1. A schematic illustration of the specimen and measuring point of carbonation and corrosion depth. 
Table 3 shows the types and amount of finishing materials used in this study. White color finishes (finishing coatings and paint), which are commonly used for the surface coating of RC buildings, were applied to the specimens, with a standard technique. A total of 7 types of finishing materials including penetrant (impregnation) were used. Four different finishes were applied to a $90 \times 400 \mathrm{~mm}$ surface of each one specimen, in the shapes of $90 \times 100 \mathrm{~mm}$ rectangular (Figure 1). This made a pair of concrete block specimens covered with 7 types of finishes including one surface area without a finish (fair-faced concrete). The specimens were then coated with epoxy resin, except for the surfaces covered with finishing materials and their opposite sides without finishes. The surface finishes were applied by experts.

Before the application of surface finishes, some specimens were subjected to accelerated carbonation curing for 8 weeks under the conditions of $20^{\circ} \mathrm{C}, 60 \%$ R.H. and $5 \% \mathrm{CO}_{2}$, to be examined the iron corrosion in carbonated areas. The prepared specimens were used for constructing the model building and were subjected to outdoor exposure test.

Table 3. Finishing materials.

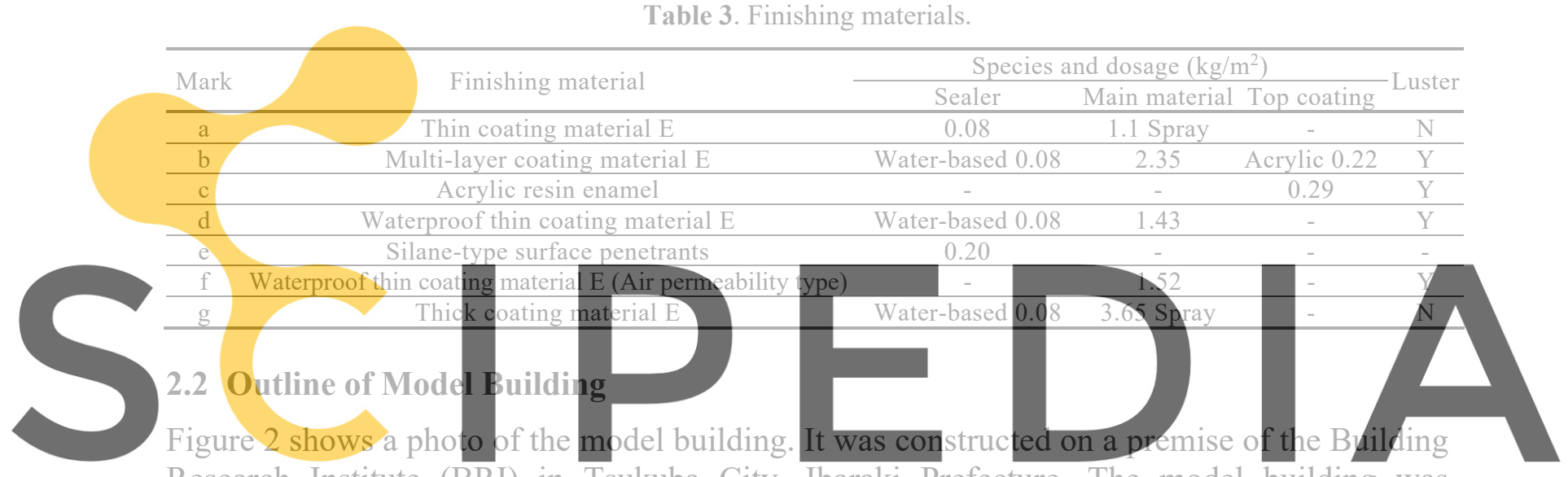

Research Institute (BRI) in Tsukuba City, Ibaraki Prefecture. The model building was

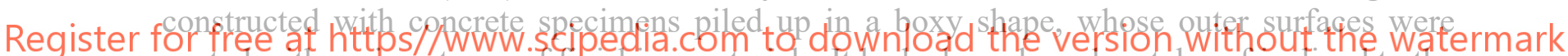
coated with varlous types of finishing materials. It had a box-shaped metal roof inclined to the north side. Inside of the building was sheltered from rain, and its room air temperature and humidity were not controlled.

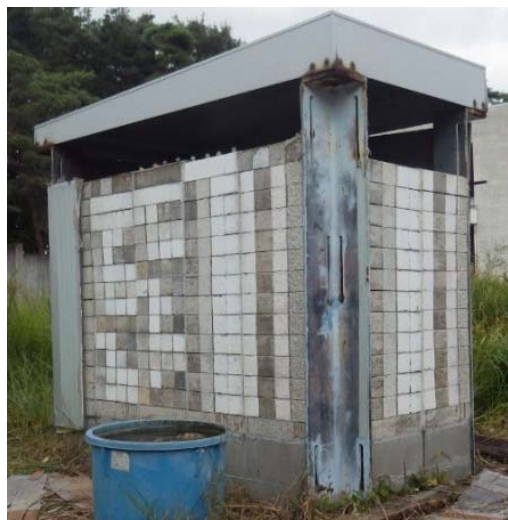

Figure 2. A photo of the model building.

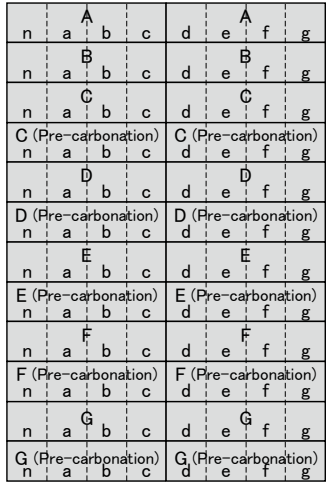

Figure 3. A layout of surface finishes. 
Figure 3 shows the layout of surface finishes. The specimens on the south side of the model building were used for the study. From heights of $460 \mathrm{~mm}$ above the ground, the specimens were piled up in 12 layers. The gap between the top of the wall and the metal roof was covered with plywood. A pair of concrete specimens with the same mix proportions were placed horizontally next to each other. A total of 7 different finishes were applied to the pair of specimens in the same layer. The capital letters in Figure 3 indicate the marks of concrete specimens (Table 2), and the lower-case letters indicate the types of finishes applied to the specimens (Table 3). The lower-case letter " $n$ " indicates the specimens without finishes.

\subsection{Test Methods}

\subsubsection{Evaluation of the surface finish deterioration}

The deterioration of finishing materials was evaluated by peeling, cracking, dirt, and chalking. It was graded by multiple experts, using a 6-degree scale from 0 (no deterioration) to 5 (severe deterioration).

\subsubsection{Measurement of carbonation depth}

As shown in Figure 1, the carbonation depth was measured by splitting a concrete specimen evenly at the center of each finishing material, and then spraying $1 \%$ phenolphthalein solution over a freshly exposed surface of the specimen. It was measured at two sets of three points,

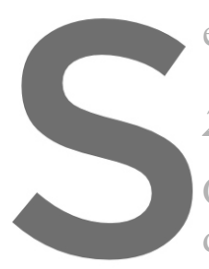
each of inner and outd

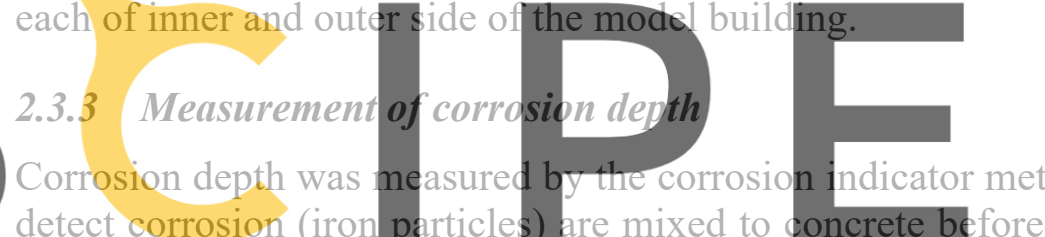

detect corrosion (iron particles) hre mixed to concrete before casting sethat the depth of rust can be measured by splitting the hardened concrete specimens. Since the rusted iron particles

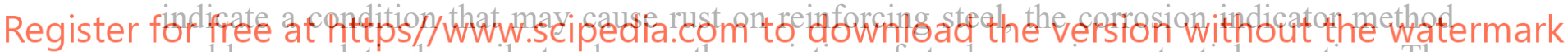
enables us relattvely easily to observe the variation of steel corrosion potential over time. The corrosion depth was measured at the same points as those of the carbonation depth measurement (Figure 1).

\section{Results and Discussion}

\subsection{Deterioration of Finishing Materials}

The finishing materials that are the type to form coating film on the surface, except silanetype surface penetrants (e), were evaluated for deterioration in Figure 4.

Acrylic resin enamel (c) shows the highest degree of peeling. One possible reason is that there was a loss of adhesion between the paint and the surface it's placed on due to long-term outdoor exposure, because a paint finish such as acrylic resin enamel has a thickness from several tens to hundred microns, while other ordinary finishes have thickness of 1-5 mm.

Multi-layer coating material E (b), acrylic resin enamel (c), waterproof thin coating material E (d) and waterproof thin coating material E (air permeability type) (f) showed high degrees of cracking. Though small in width (hairline crack), cracks in the specimens are often caused by the degradation of resin contained in finishing materials due to ultraviolet ray. 
All finishes showed the deterioration degrees from 2 to 3 , except that waterproof thin coating material E (d) remained lower levels of dirt. The adhesion of dirt is affected by the nature of surface finishing materials such as hydrophilicity, hydrophobicity, water absorbability, and water repellency. The smoothness and fineness of surface finishing materials are considered to be lost due to long-term outdoor exposure.

Multi-layer coating material E (b), acrylic resin enamel (c), waterproof thin coating material E (d) and waterproof thin coating material E (air permeability type) (f) showed high degree of chalking. Surface finishing material is usually a composite material containing aggregates and admixture that add thickness to surface, coloring agent to add color, and bonding material to bind them together. Degradation of bonding material and coloring agent is one of the reasons that cause chalking, which refers to the formation of fine powder on the surface of the paint film.

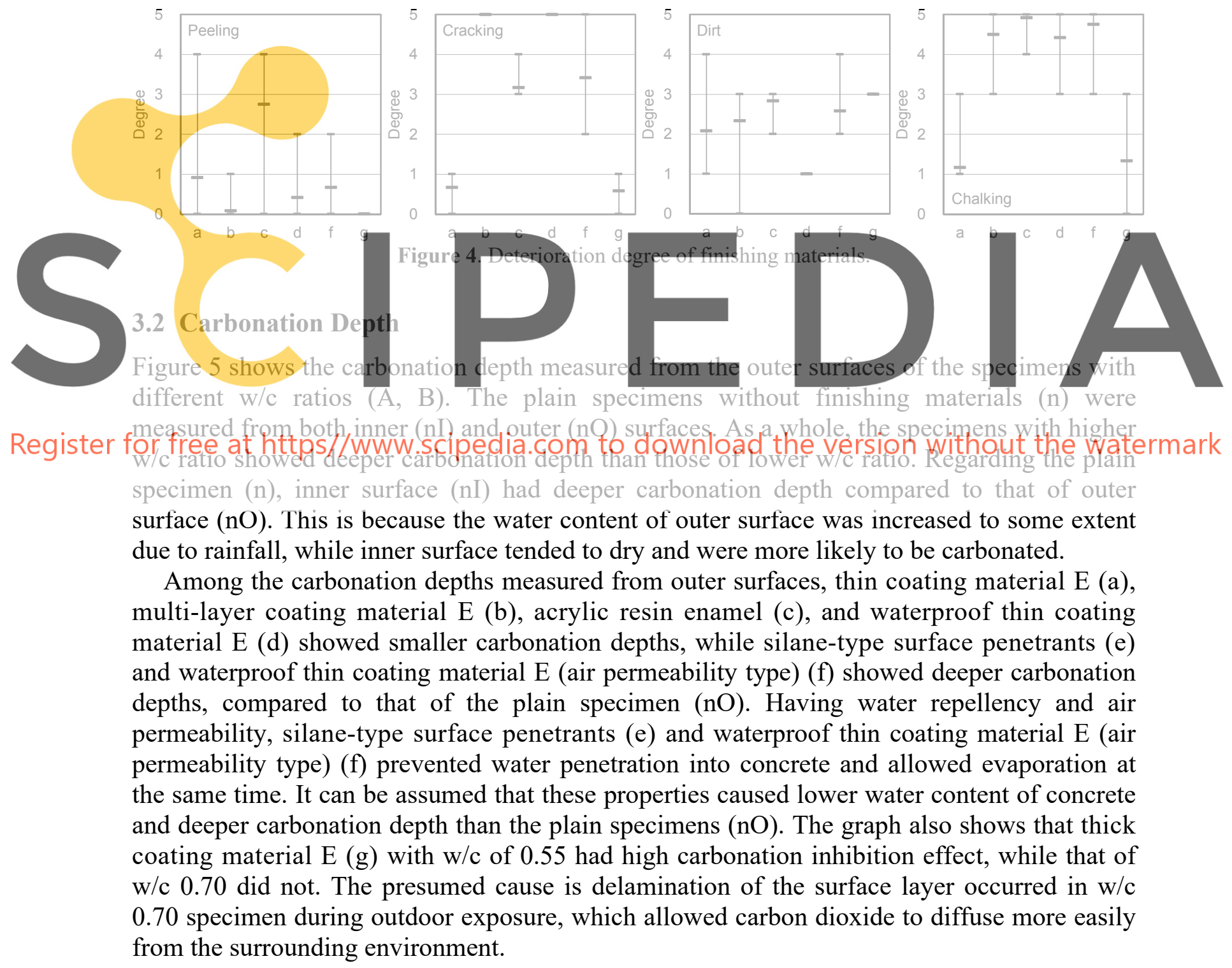


Assume the ratio of carbonation depth of a specimen covered with finishing material to that of a plain specimen not covered with finishing material shows constant value. $S(t)$ is the carbonation rate representing the carbonation inhibition effect, and can be expressed by the following formula (1) (Nagase et al., 2007).

$$
S(t)=\frac{C_{C}(t)}{C_{B}(t)}
$$

Here, $S(t)$ is carbonation rate at the time of exposure (time), $C_{C}(t)$ and $C_{B}(t)$ are carbonation depth of concrete covered with and without finishing material, respectively $(\mathrm{mm})$.

Figure 6 shows the carbonation rate of finishing materials at the age of 30 years applied to the model building. Among them, multi-layer coating material E (b) and waterproof thin coating material E (d) showed particularly low rates, suggesting they have high carbonation inhibition effects. In addition, thick coating material $\mathrm{E}(\mathrm{g})$ would also have high carbonation inhibition effect, if it demonstrated its potential efficacy.
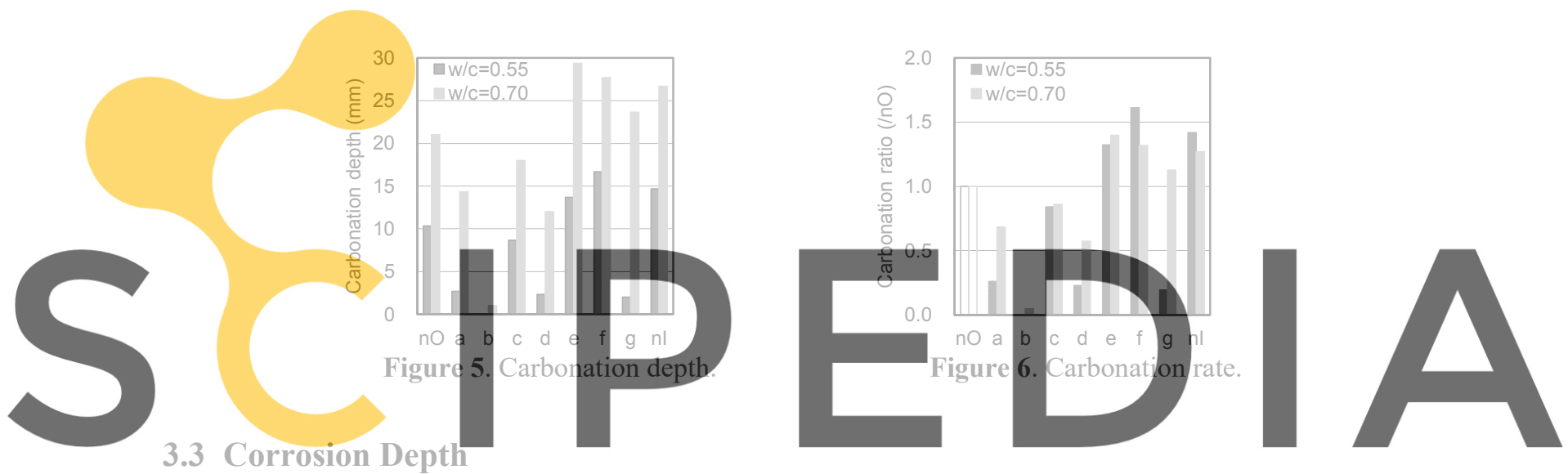

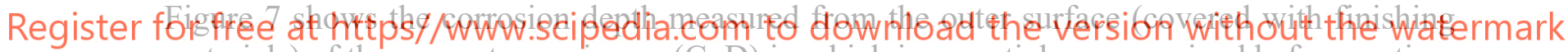
materials) of the concrete specimens (C, D) in which iron particles were mixed before casting. The plain specimens without finishing materials (n) were also measured from both inner (nI) and outer $(\mathrm{nO})$ surfaces. As with the carbonation depth, specimens with higher w/c ratio showed deeper corrosion depth than those with lower w/c ratio. This indicates that higher w/c ratio make reinforcing steel more prone to corrosion. The graph also shows that the plain specimens (n) showed deeper corrosion depth, when measured from inner surface (nI) than from outer surface $(\mathrm{nO})$.

Comparing the corrosion depth measured from outer surfaces, multi-layer coating material E (b), waterproof thin coating material E (d), and thick coating material E (g) had a smaller depth of corrosion than that of plain specimen (nO). Multi-layer coating material $\mathrm{E}$ (b) and waterproof thin coating material E (d) are considered to have relatively higher water repellent effect than other finishing materials. Though carbon dioxide may have permeated concrete from the delaminated surface, thick coating material $\mathrm{E}(\mathrm{g})$ is considered to have been effective in preventing water penetration.

The pre-carbonated specimens tended to have deeper corrosion depth, which was especially true for those with w/c 0.70 . This indicates that reinforcing steel is more likely to corrode in carbonated area. 

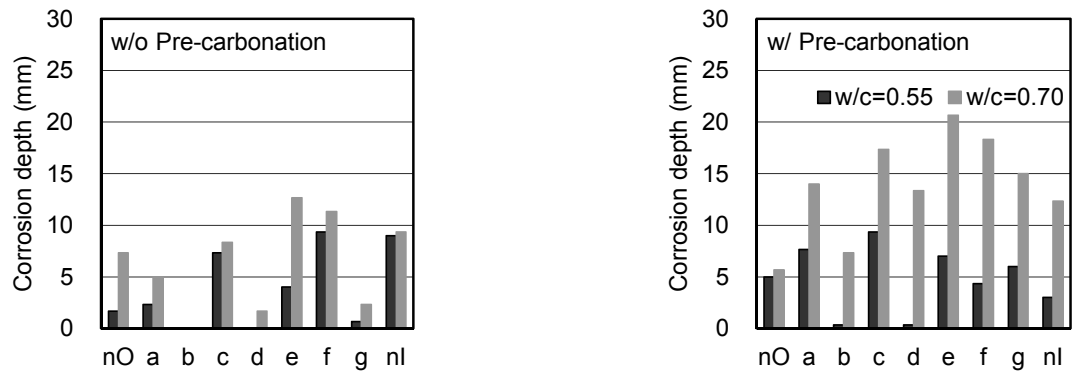

Figure 7. Corrosion depth.

Figure 8 shows the relationship of the corrosion depth to the amount of chloride ions in the specimens of w/c 0.70 (D, E, F, G), in which iron particles and chloride ions had been added before casting. Again, the pre-carbonated specimens tended to have deeper corrosion depth compared to those without pre-carbonation. However, the amount of chloride ions, including its presence or absence, did not show significant effects on the corrosion depth.
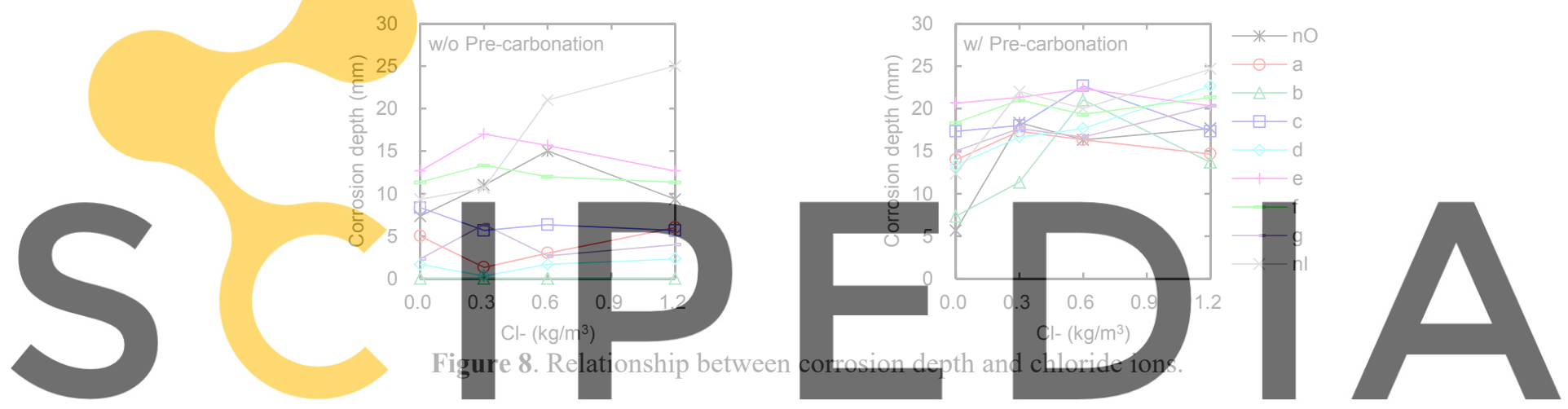

3.4 Relation between Corrosion Depth and Carbonation. Depth

Register for free at https//Www.scipedia.com to download the version without the watermark

Figure 9 shows the relationship between the corrosion depth and carbonation depth measured

from the outer surfaces of the concrete specimens (C, D) in which iron particles had been

mixed before casting. The depths measured at 3 points on each finishing material are plotted on the graph. The progress of corrosion is preceded by that of carbonation. This suggests that the corrosion is not initiated immediately after the carbonation front reaches reinforcing steel. It can be assumed that when the concrete surface is properly coated by finishing material, corrosion may not be initiated in non-carbonated area where the $\mathrm{pH}$ level is not lowered.
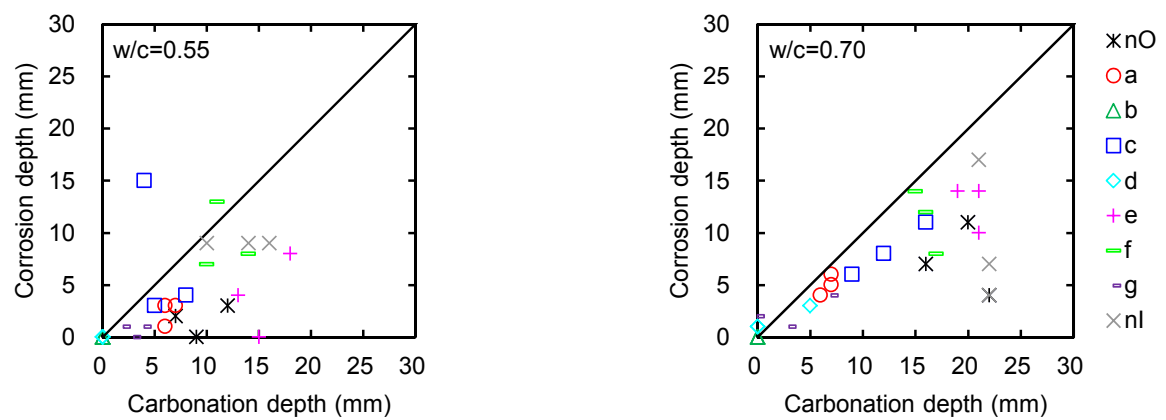

Figure 9. Relationship between corrosion depth and carbonation depth. 


\section{Conclusion}

In this study, a model building made out of concrete block specimens whose surfaces were coated with various finishing materials was constructed for the outdoor exposure test. After 30 years of outdoor exposure, the deterioration of the finishing materials and their carbonation and corrosion inhibition effects were investigated. As a result, the following conclusions were obtained.

- Though the deterioration levels differed depending on their types and thickness, all finishing materials showed some kind of deterioration after 30 years' long-term outdoor exposure.

- The progress of carbonation is prevented when the surface is coated with finishing materials of sufficient thickness or waterproof effect. However, the carbonation inhibition effect cannot be obtained when using air-permeable finishing materials or there is a peeling finish on the surface.

- The progress of corrosion is prevented when the surface is coated with finishing materials of sufficient thickness or waterproof effect.

- Regarding the relationship between corrosion depth and carbonation depth, corrosion is initiated after the carbonation front reaches the area. It usually takes a while to initiate corrosion in the carbonated area, not immediately after the carbonation reaction.

When the concrete surface is properly coated with finishing material, corrosion may

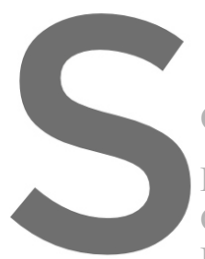
not be initiated

ORCID

Koichi Matsuzawa: http:

Osamu Senbu: https://orcid

Kei-ichi Imamoto: https:
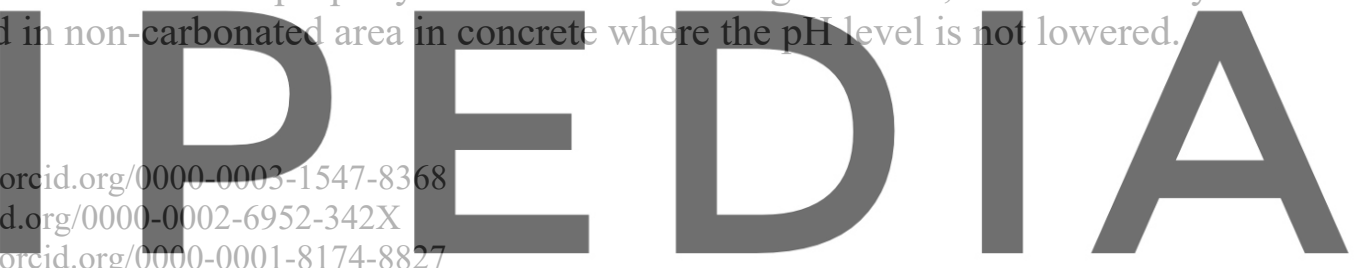

Chizuru Kiyohara: https://orcid.org/0000-0003-1286-9056

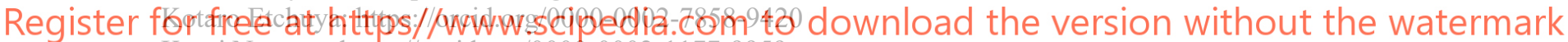

Kaori Nemoto: https://orcid.org/0000-0002-1177-9959

\section{References}

Hasegawa, T. et al. (2002). A study on the corrosion protection effects of surface finishing materials using a model building at the afe of eleven years. J. Struct. Constr. Eng., AIJ, No.560, 27-33. (in Japanese)

Hasegawa, T. et al. (2017). Detarioration and preventitive effect of finishing materials against carbonation and corrosion of reinforcing bars in concrete based on twenty year outdoor exposure test using model building. $J$. Struct. Constr. Eng., AIJ, No.733, 337-346. (in Japanese)

Senbu, O. et al. (1987). A proposal of corrosivity test for reinforced concrete. Summaries of Technical Papers of Annual Meeting, AIJ, 289-290. (in Japanese)

Nagase, K. et al. (2007). Evaluation of various finishing materials contributing to carbonation suppressive of concrete in structures Part1-Part8. Summaries of Technical Papers of Annual Meeting, AIJ, 1123-138. (in Japanese) 